\title{
Development of Assembly Line Layout for Measurement of Work
}

\author{
R.N. Panchal ${ }^{1}$, A.D. Awasare ${ }^{2}$, A.M. Zende ${ }^{3}$, H.M. Kumbhar ${ }^{4}$ \\ Professor and HOD, Mechanical Engineering Dept, AGTI's DACOE Karad, India ${ }^{1}$ \\ Assistant Professor, Mechanical Engg. Dept, AGTI's DACOE Karad, India ${ }^{2}$ \\ Professor, Civil Engineering Dept, AGTI's DACOE Karad, India ${ }^{3,4}$
}

\begin{abstract}
Assembly is an important manufacturing process in terms of mass production system. Significant research has been done in the Design and operations of assembly systems in support of high product variety, but many opportunities exist for future research. The paper contains practical mapping and product flow from start to finish. The information would highly assist the researcher to visualize the current state of the activity mapping the material and information flow. In this paper first review the state of the art research in the areas of assembly system design, planning and operations in the presence of product variety. Work measurement is essential for both the planning and control of operation.
\end{abstract}

Keywords: Design, Planning, Operation, Work measurement.

\section{INTRODUCTION}

The concept of production assembly line (AL) was first introduced by Henry Ford in the early 1900's as shown in fig.1.1. It was designed to be an efficient, highly productive way of manufacturing a particular product. The basic assembly line consists of a set of workstations arranged in a linear fashion, with each station connected by a material handling device. The basic movement of material through an assembly line begins with a part being fed into the first station at a predetermined feed rate. A station is considered any point on the assembly line in which a task is assembling the part. These tasks can be performed by machinery, robots, and or operators. Once the part enters a main line, a task is then performed on the part, and the part is fed to the next operation. The time it takes to complete a work at each operation is known as the process time. The cycle time of an assembly line is predetermined by a production rate required. This production rate is set so that the amount of end product is produced within a defined time period.

One of the main issues concerning the development of an assembly line is how to arrange the work to be performed. This arrangement may be somewhat subjective, but has to be dictated by implied rules set forth by the production sequence. For the manufacturing of any work, there are some sequences of tasks that must be followed. The assembly line balancing problem originated with the invention of the line. However, during the initial years of the assembly line's existence, only reputable methods were used to balance the lines. Since then, there have been numerous methods developed to solve the different forms of the line balancing. Development of new assembly line and then rebalancing of the assembly line is having need to from the production point of view. As most of the small scale and medium scale industries are not follow the various methods available such that RPW etc, for line balancing or even line developing which may cause the loss of the productivity and time.

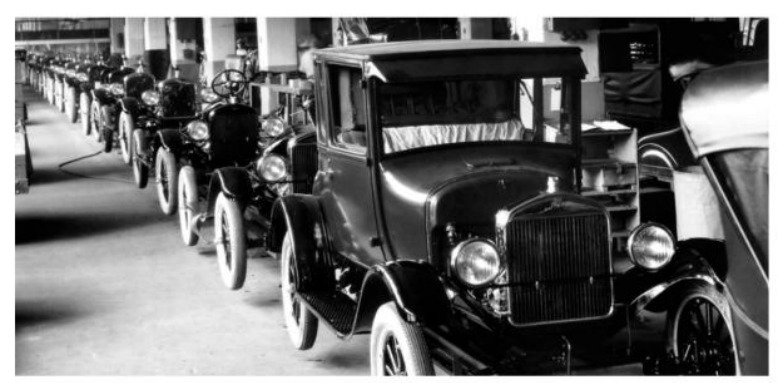

Fig.1.1 An old photo of the Ford Model T assembly line

An assembly line balancing (ALB) consists of a finite set of work elements or tasks, each having an operation processing time on work and a set of precedence relations for tasks which specify the required orderings of the tasks. One of the problems organizing for mass production is how to group work tasks to be perform to allocate an equal amount of work to each work station along the assembly line. The fundamental line balancing problem is to assign a set of tasks to an ordered set of work stations, so that the precedence diagrams relations are satisfied and some measure of performance is to be balanced. Process layout, product or line layout and fixed-position layout are 3 basics types of layout. This project is based on product layout. Product layout is defined as shop flower area, where number of stations and work processes are arranged so that the products will pass through several workstations. Due to high demand the resources were rearranged from 
IARJSET

process layout to product layout. This required a sequence steps to make product. Industries often called as an assembly line. The aims of the study are improving the productivity and efficiency of an assembly line in industry. The objectives are to redesign the layout to improve line performance. Simulation is implemented in this project in order to analyse and investigate the problems occurring in assembly line.

\section{LITERATURE REVIEW}

Johan Hakansson et al. [1] have focused on mixed-model assembly line balancing and sequencing problems, including different line layouts. The study was undertaken in collaboration with a company to assist in mapping current state of the art. Balancing problems affect businesses long-term strategic decisions and are complex problems with regard to installation and rebalancing of assembly lines. Sequencing concerns decisions of shortterm problem sequencing approaches include level scheduling, mixed-model sequencing. Level scheduling constructs a sequence of variants to create efficient deliveries supported by the just-in-time concept, whereas both mixed-model sequencing aim to minimize violations of a work station's capacity through constructing a sequence, which alternates variants with high and low work intensity. Five layouts were considered, single, mixed-model, multimodal, two-sided and u-shaped assembly lines. These layouts were evaluated on the basis of the manufactured products, size and space at the production plant, economic resources, number of required operators and machinery.

Christian and Armin [2] had carried work on Assembly lines. Those are traditional and still attractive means of mass and large-scale series production. Since the early times of Henry Ford several developments took place which changed assembly lines from strictly paced and straight single-model lines to more flexible systems including, among others, Lines with parallel work stations or tasks, customer-oriented mixed-model and multi-model lines, U-shaped lines as well as unpaced lines with intermediate buffers. In any case, an important decision problem, called assembly line balancing problem, arises and has to be solved when configuring an assembly line. It consists of distributing the total workload for manufacturing any unit of the product to be assembled among the work stations along the line. Assembly line balancing research has traditionally focused on the simple assembly line balancing problem (SALBP) which has some restricting assumptions.

Roy and Khan [3] has presented Assembly Line production is one of the widely used basic principles in production system. The problem of Assembly Line Balancing deals with the distribution of activities among the workstations so that there will be maximum utilization of human resources and facilities without disturbing the work sequence. Research works mainly deals with minimization of idle time subject to precedence constraints. Lack of uniqueness in their optimum solutions has led to the present work where minimization of both balancing loss and system loss has been envisaged under the usual precedence constraints. The researchers suggested a generic approach for designing of an assembly line where, with a given number of workstations, one can efficiently arrive at the desired solution under different methods of search like simulation, heuristic etc. Thus, the main aim of this research is to redefine the objective of the Assembly Line Balancing Problem and sequentially handle Balancing Loss and System Loss.

Francesco Longo et al. [4] discussed the effective design of an assembly line for heaters production. Considering that the real plant still doesn't exist, simulation has been used as cognitive tool. The simulation results highlight problems concerning high stress levels for some workers due to legs bending and ergonomic risks related to lifting tasks The design of an assembly line and its workstations is characterized by two critical factors, the line balancing and the ergonomic optimization of each single workstation. The line balancing is strictly related to the number of workstations, process and set-up times, type of operations hand operated or automated. The ergonomic analysis allows evaluating potential hazard, musculoskeletal disorders, risks related to excessive weights as well as specific risk factors concerning lifting tasks or energy expenditure for the operation being performed.

Ponnambalam et al.[5] studied a multi-objective genetic algorithm to solve assembly line balancing problems. The performance criteria considered were the number of workstations, the line efficiency, the smoothness index before trade and transfer, and the smoothness index after trade and transfer. The developed genetic algorithm is compared with six popular heuristic algorithms, and rank and assign heuristic methods. For comparative evaluation, 20 networks were collected from open literature, and were used with five different cycle times. All the six heuristics and the genetic algorithm are coded in $\mathrm{C}++$ language. It was found that the proposed genetic algorithm performs better in all the performance measures than the heuristics. However, the execution time for the GA is longer, because the GA searches for global optimal solutions with more iteration.

M.A. Hannan et al.[6] Studied Line balancing is the phase of assembly line study that nearly equally divides the works to be done among the workers so that the total number of employees required on the assembly line can be minimized. As small improvements in the performance of the system can lead to significant monetary consequences, it is of utmost importance to develop practical solution procedures that may yield a significant enhancement in the throughputs of production. 
IARJSET

International Advanced Research Journal in Science, Engineering and Technology

National Conference on Design, Manufacturing, Energy \& Thermal Engineering (NCDMETE-2017)

AGTI's Dr. Daulatrao Aher College Engineering, Vidyanagar Extension, Karad

Vol. 4, Special Issue 1, January 2017

\section{FOUR FUNDAMENTAL STEPS TO DEVELOPMENT OF ASSEMBLY LINE LAYOUT AT COMPANY}

There are four fundamental steps or stages involved in applying the Implementation Strategy to achieve assembly line in a process, division, or company. These phases are:

1. Identify the problem:- The $\mathrm{U}$ line layout it is better for the mass production where the variety are to be low but the major challenge is that the proper integration is required to reduce the time and increase the capacity for assembly as well as fulfil the demand of customer. In case of the existing assembly line all the material which are come on every assembly station but problem is that engagement of man power and utilization of the space is high so company need to develop new assembly line. For proposed assembly line designed a new fixture contains kitting attachment for placement of all parts required for assembly.

2. Define the scope \& requirements:-Bottle necking and excessive workers are common problems rose in assembly line. These are the major problems that removed and yet require being solution as soon as possible. Manufacturers are often encounters this problems and if this happen it will be decreased the line efficiency and the required work rate. In preventing these problems, engineers should come out with a solution in order to fix these problems. One way to do so is using line balancing method. This aim is to minimizing job performance and operators on the assembly line while meeting a required output.

3. Define the goals \& objectives: - i) Maintains or improve product quality, reduce damage and provide protection for materials ii) Give safety and improve working conditions iii) Increase productivity iv) To maintain inventory by decreasing storage requirement v) To give efficient flow of materials

4. Define the time-scales: The application of techniques designed to establish the time for qualified worker to carry out a specified job at a define level of performance.

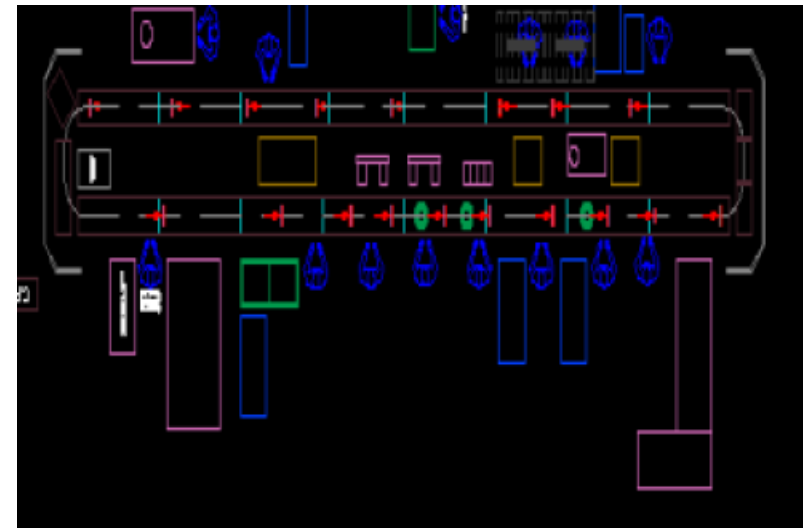

Fig.1.2. U shape Layout
Manufacturing factory area analysis are invaluable tools in the implementation of waste reduction manufacturing. Many manufacturers will not make a change to the process before a simulation is performed to determine the impact of the change. Analysis can be considered as inexpensive insurance against costly problems. A high volume manufacture was evaluating several alternative layouts for their proposed assembly facility. After an initial review, layout was selected upon which to apply their limited simulation resources as shown in fig.1.2. The $U$ shape layout is considered for assembly work having total 21 work stations.

\section{ANALYSIS STEPS AND RESULTS}

Time study: Time study is the combination of eight steps of activities which are used for developing the standard time of a projected task. Eight steps of activities are discussed below:

Step 1: Define the task- In this step; a work should be selected for time study according to the assembly.

Step 2: Divide the task into sub elements.

Step 3: Decide how many to measure the task -numbers of job cycle.

Step 4: Time and record elemental times and rating of performance-Recording the time can be done by a stopwatch. When observation time will be taken for an operation, simultaneously normal performance rating should be recorded for the related worker.

\section{* Performance timing}

Performance rating is the assessment of the workers rate of working relative to the observer's concept of the rate corresponding to the standard pace

Performance rating $=$ Normal rating / Standard rating* Standard rating

The standard level is the average rate at which qualified workers will naturally work at a job, when using the correct method and the employees are motivated to apply themselves to their work For standard rating following three conditions must be ensured. 1. Skilled workers 2. Right method 3.Energetic workers.

\section{* Normal rating}

It is the average rate at which a worker will naturally work even he has no specific motivation to apply himself to his work Rating factors:

- The figure 100 represents standard performance.

- If the operator is apparently with less effective speed, than the assignment factor are less than 100.

- If, on the other side, the effective rate of working is above standard, the worker gets a factor above 100 .

- Performance rating will follow the subsequent relation: Repeated time $\mathrm{x}$ performance rating $=$ constant

Step 5: Compute the average observed time

In this step, average observed cycle time should be measured form the collected observed time data of step 4 . Average observed time $=$ Sum of the times recorded to perform each element of job /Number of times repeat. 
IAR JSET

International Advanced Research Journal in Science, Engineering and Technology

National Conference on Design, Manufacturing, Energy \& Thermal Engineering (NCDMETE-2017)

AGTI's Dr. Daulatrao Aher College Engineering, Vidyanagar Extension, Karad

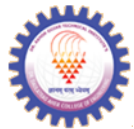

Vol. 4, Special Issue 1, January 2017

Step 6: Determine the performance rating then compute the normal time for each element

Normal time should be measured by using the following equation Normal time $=$ (Repeated cycle time) $\mathrm{x}$ (performance time rating)

Step 7: At the normal times for each element to develop a total normal time for the task required allowance should be added with normal time to make it standard and usable for the employee. Allowance is the amount of time added to the normal time for personal needs, unavoidable delays, and fatigue. Allowances include time for labour fatigue and personal needs, equipment's breakdown, rest periods, information delays, and so on. Mainly the following allowance should be considered for perfect time: Workshop allowance Fatigue relax \& physical allowance. Step 8: Compute the perfect time finally; the standard time should be measured by the following equation as Standard time $=$ Total normal time / (1-Allowance time factor.

In many assembly plants, standard push production systems with dozens of workers are being reorganized into straight assembly lines. In particular departments the Standard time (St) for each operation is calculated by the sum of the base time $(\mathrm{Bt})$, the fatigue allowances $(\mathrm{Fa})$ and the idle time (It). The base time consists of the observed time Ot and the actual operation time rating Or. It is calculated as follows $\quad \mathrm{Bt}+\mathrm{Fa}+\mathrm{It}=\mathrm{Ot} \times \mathrm{Or}+\mathrm{Fa}+\mathrm{It}$ The line balancing problem of assembly shops is solved by using St, and it's assumed that all of the same operations are processed equally. However, in reality, all operations are completed at different times because of their stochastic structure, and the stochastically of operations makes it almost impossible to follow a fixed time pattern. Therefore, supervisors are up against unexpected queues and decreasing levels of performance during the assembly process. New calculation methodology which reflects real better is needed in order to estimate more realistic production quantities and performance.

Table I. Time calculation for assembly layout

\begin{tabular}{|l|c|}
\hline Task On Workstations & Time in Sec \\
\hline Operation No-1 & 13.95 \\
Operation No-2 & 12.96 \\
Operation No-3 & 4.32 \\
\hline Walking Time & 31.23 \\
\hline Operation No-4 & 13.77 \\
Operation No-5 & 18.02 \\
\hline Walking Time & 31.79 \\
\hline Operation No-6 & 14.27 \\
Operation No-7 & 6.6 \\
Operation No-8 & 15.80 \\
\hline Walking Time & 36.68 \\
\hline Operation No-9 & 4.05 \\
Operation No-10 & 6.21 \\
Operation No-11 & 12.69 \\
Operation No-12 & 1.61 \\
\hline Walking Time & 24.57 \\
\hline Operation No-13 & 15.39 \\
\hline
\end{tabular}

\begin{tabular}{|l|c|}
\hline Operation No-14 & 13.50 \\
Operation No-15 & 5.67 \\
Operation No-16 & 15.39 \\
\hline Walking Time & 34.56 \\
\hline Operation No-17 & 15.39 \\
Operation No-18 & 4.05 \\
Operation No-19 & 13.65 \\
\hline Walking Time & 33.09 \\
\hline Operation No-20 & 17.01 \\
Operation No-21 & 21.18 \\
\hline
\end{tabular}

\section{FUTURE SCOPE}

New numerical tool can be used to predict the production behaviour. In order to increase current production rate, the motion study and time study can be done in future and there is the scope of implementations of the techniques like MOST. With the use of advance software like WITNESS, Simul8, Flexsim simulation is possible. Layout optimization analysis made such that relative location areas for activities involved. Also it is possible to add lean manufacturing tool for assembly line.

\section{ACKNOWLEDGEMENTS}

We express our deep sense of gratitude to Mechanical Engineering Department of AGTI's DACOE, Karad. We acknowledge with thanks to faculty, teaching and nonteaching staff of the department, Central library and Colleagues. We would like to thank the Emerson Climate Technologies, Atit for their cooperation.

\section{REFERENCES}

[1] Johan Hakansson, Emil Skoog, och Kristina Eriksson, "A review of assembly line balancing and sequencing including line layouts", University west Department of Engineering Science 46186 Trollhattan.

[2] Christian Becker and Armin Scholl "A survey on problem and methods in generalized assembly line balancing”, European Journal of Operational Research $168,694-715.2006$.

[3] D Roy and D Khan, "Assembly line balancing to minimize balancing loss", The International Journal of Industrial engineering, 6 (11), 1-5, ISSN: 1735-5702.

[4] Francesco Longo, Giovanni Mirabelli and Enrico Papoff. "Effective design of an assembly line using modeling \& simulation", Proceedings of the 2006 Winter Simulation Conference.pp18931898, 2006.

[5] Ponnambalam, P.Aravindan and G. Mogileeswar Naidu. "A MultiObjective Genetic Algorithm for Solving Assembly Line Balancing Problem". The International Journal of Advanced Manufacturing Technology. 16, 341-352, 2000.

[6] M. A. Hannan, H.A. Munsur, M. Muhsin, "An Investigation Of The Production Line For Enhanced Production Using Heuristic Method" International Journal of Advances in Engineering \& Technology, ISSN: 2231-1963, Nov 2011.

[7] D.J. Fonseca1, C.L. Guest, M. Elam, And C.L. Karr, "A Fuzzy Logic Approach To Assembly Line Balancing" Math ware \& Soft Computing 12 (2005), 57-74.

[8] S.T.Ghutukade and Dr. S.M.Sawant "Use of Ranked position weighted method for assembly line balancing" International Journal of Advance Engineering Research and Studies. E-ISSN22498974.vol II, Issue III, April- June, 2013. 